\title{
(Des)valorização do curso de Pedagogia?
}

\author{
Margarete Bertolo Boccia* \\ Mônica de Ávila Todaro**
}

\begin{abstract}
Resumo
O presente texto visa divulgar parte dos resultados de pesquisa docente realizada a partir do projeto "O curso de Pedagogia e os processos formativos". Versa sobre as críticas que o curso de Pedagogia vem recebendo de alguns estudiosos da área, de modo a questioná-las e analisá-las. Apresenta um recorte histórico demonstrando que, em vários momentos, o curso de pedagogia é desprestigiado e pouco valorizado e que ainda busca sua identidade. A pesquisa documental realizada deteve-se em identificar como os estudos sobre o curso e sobre a formação de professores tratam o assunto, identificando o Estado da Arte da formação inicial de professores no Brasil em bases digitais de teses e dissertações. Constatou-se que este não é o tema mais estudado e abordado, caracterizando-se um problema a ser investigado mais profundamente de modo a ampliar a discussão acerca do curso de Pedagogia.

Palavras-chave: Pedagogia; Formação inicial de professores.
\end{abstract}

\begin{abstract}
This paper aims to disseminate the results of a research conducted as part of the project "Pedagogy course and formative processes". It addresses the criticism that the Pedagogy course has been receiving from some scholars in the field, in order to question and analyze it. It presents an historical view, demonstrating that, in various moments, the Pedagogy course has been discredited and undervalued and that it is still seeking its identity. The documentary research focused on identifying how studies on the course and the teacher training efforts treat the subject, identifying the State of the Art of the initial teacher training in Brazil in theses and dissertations databases. It was found that this is not one of the most studied and discussed subjects, which consists of a problem to be further investigated in an attempt to expand the discussion on the Pedagogy course.
\end{abstract}

Keywords: Pedagogy; Initial teacher training.

\section{Introdução}

Freire (1992) nos ensina que

uma das tarefas do educador ou educadora progressista, através da análise política, séria e correta, é desvelar as possibilidades, não importam os obstáculos, para a esperança, sem a qual pouco podemos fazer porque dificilmente lutamos e quando lutamos, enquanto desesperançados ou desesperados, a nossa é uma luta suicida, é um corpo-a-corpo puramente vingativo (p.02).

$\mathrm{O}$ que haveria em comum entre as críticas tecidas ao longo do processo histórico em relação ao curso de Pedagogia e as ideias de Paulo Freire? Na busca de uma formação de professores que implique em consciência crítica, acredita-se que a leitura das obras de Freire contribua para nos tornar capaz de analisar os estudos sobre o curso de Pedagogia à luz de seus escritos.

A compreensão da natureza complexa da

\footnotetext{
* Endereço eletrônico: maggie.boccia@uninove.br
}

** Endereço eletrônico: mavilatodaro@ uninove.br instituição de ensino superior constitui o alicerce que sustenta os argumentos defendidos ao longo do texto. Para Gadotti (2010), "a formação e o trabalho do educador inserem-se numa estratégia políticopedagógica de transformação social na qual a educação deveria se constituir num fator importante" (p.16). Nesse sentido, analisar o que se tem dito a respeito dos cursos de Pedagogia pode ser interessante se tal tema não for entendido desconectado do contexto histórico-social e se formos além da simples tomada de consciência.

A conscientização que buscamos é compreendida por Freire como processo de criticização das relações consciência-mundo e é condição para a assunção do comprometimento humano diante do contexto histórico-social (STRECK, REDIN, ZITKOSKI, 2008).

$\mathrm{O}$ artigo que se segue foi escrito mergulhado na esperança de que a conscientização da trajetória imposta ao curso de Pedagogia e das críticas feitas por estudiosos ao mesmo nos leve à esperança no processo de fazer e refazer o mundo.

Numa primeira parte, apresentamos as críticas em torno do curso de Pedagogia e da 
implicação deste na formação do futuro educador.

Num segundo momento, nos detemos na desvalorização do curso em questão apontando as limitações e desafios surgidos ao longo do tempo.

No último tópico tentamos ampliar nosso olhar e o do leitor, trazendo os números que indicam a preocupação dos pesquisadores com o tema.

Por fim, colocamos em nossas considerações finais algumas de nossas esperanças que mesmo entrando em contato com tamanhas dificuldades na prática e na teoria não nos escapam dos olhos.

\section{Críticas ao curso de Pedagogia}

O curso de Pedagogia de alguns anos para cá tem sido o foco de duras críticas que giram em torno das questões da formação desse profissional. As Diretrizes Curriculares Nacionais para o Curso de Pedagogia, após sua aprovação e publicação em 2006, indicam que o curso destina-se prioritariamente a formação de professores. Desde então, o curso vem recebendo as "culpas" por questões relacionadas à qualidade da educação e principalmente do ensino nas escolas brasileiras.

A estrutura do curso vem sofrendo críticas de estudiosos, educadores e até mesmo do Ministério da Educação. Este último apresenta-se com certo ar de preocupação frente ao crescimento de oferecimento e demanda e em seu site apresenta dados de ampliação do número de cursos de Pedagogia oferecidos, bem como proporcionalmente $\mathrm{o}$ aumento do número de alunos/professores formados por esse curso. Apresentado apenas como um dado, o MEC não expressa, digamos, satisfação por esses números, que a nosso ver deveriam ser analisados assim, visto que os objetivos propostos nas legislações pertinentes ao tema, seja a LDB ou as próprias diretrizes, estariam sendo atingidos.

$\mathrm{O}$ site publica o seguinte texto, no item qualificação do professor, em 03 de fevereiro de 2011:

$O$ número de professores formados em pedagogia praticamente dobrou em sete anos, segundo dados do Censo do Ensino Superior realizado pelo Instituto nacional de Estudos e pesquisas Educacionais (Inep). Em 2002, o levantamento registrou a formatura de 65 mil educadores em pedagogia; em 2009, esse número subiu para 118 mil. No mesmo período, o censo mostra que aumentaram em mais de $60 \%$ as matrículas nessa área de ensino - de 357 mil em 2002 para 555 mil em 2009. Também o ingresso aumento no intervalo analisado - de 163 mil novos estudantes para 190 mil, o que representa evolução de 20\%. (portal do MEC).

Se o item do site refere-se à qualificação de professores, porque apenas números são informados? Por que tratar de maneira quantitativa o tema se estão preocupados com a qualidade dos cursos? Tais cursos não passaram por acompanhamento, chegando até alguns deles a serem fechados?

No final da página do site, informa-se que "o curso de pedagogia forma professores para trabalhar em creches, na educação, ensino fundamental regular (com turmas do primeiro ao quinto ano) e na educação de jovens e adultos correspondente ao ensino fundamental" (site Inep). E quanto à habilitação como gestores (diretores, assistentes de direção e coordenadores pedagógicos)?

A formação inicial dos pedagogos/professores/gestores é algo que merece ser investigado mais a fundo, pois se a preocupação por parte do MEC não está explícita, algumas publicações trazem críticas claras.

A antropóloga Eunice Durham, considerada uma das maiores especialistas em ensino superior brasileiro, declarou, em entrevista à revista Veja, que o curso de Pedagogia representa uma "Fabrica de maus professores". Em suas palavras: "os cursos de pedagogia são incapazes de formar bons professores". Abaixo transcrevemos uma das perguntas feitas e a resposta dada:

P: Sua pesquisa mostra que as faculdades de pedagogia estão na raiz do mau ensino nas escolas brasileiras. Como?

$R$ : As faculdades de pedagogia formam professores incapazes de fazer o básico, entrar na sala de aula ensinar a matéria. Mais grave ainda, muitos desses profissionais revelam limitações elementares: não conseguem escrever sem cometer erros de ortografia simples nem expor conceitos científicos de média complexidade. Chegam aos cursos de pedagogia com deficiências pedestres $e$ saem de lá sem ter se livrado delas. Minha pesquisa aponta as causas. A primeira, sem 
dúvida, é a mentalidade da universidade, que supervaloriza a teoria e menospreza a prática. Segundo essa corrente acadêmica em vigor, o trabalho concreto em sala de aula é inferior a reflexões supostamente mais nobres (Revista Veja, 2008).

Segundo Durham, o curso não dá conta de suas obrigações, logo se pode deduzir que os pedagogos - professores - formados pelo curso são ruins, não são competentes e comprometem a qualidade da educação e do ensino do país. E o "ataque" se mantém durante toda a explanação.

$\mathrm{Na}$ época foi grande a repercussão, muitos concordando com as colocações ou outros saindo em defesa do curso. Por exemplo, o professor Ivonaldo Leite da universidade Federal de Pernambuco, que é $\mathrm{PhD}$ em Ciências da Educação, encaminhou email em dezembro de 2008, para o Jornal da Ciência, cujo posicionamento é de defesa ao curso e análise crítica das colocações de Durham. Mas, no fundo, também apresenta uma crítica ao curso de outra ordem e mais, já desqualifica o profissional ali formado, reforçando, mesmo que não de maneira intencional, a crença de que a profissão docente seja menor ou menos qualificada.

[...] a suposta deficiência do curso de pedagogia, formando "maus professores", está intensamente relacionada ao ensino de base que os seus estudantes tiveram. Há de se reter ainda que, nos de hoje, não raramente, o ingresso em determinados cursos é menos por opção vocacional $e$ mais um função da obtenção de um diploma do ensino superior. Isto por razões das mais diversas. Assim, é de se imaginar os impactos que tal fato tem no percurso de segmentos dos estudantes, no que toca ao seu empenho para apreenderem uma formação sólida (site, Jornal da ciência, 2008).

Sobre as críticas indicadas frente à má qualidade da educação e principalmente do ensino empreendido nas escolas de nosso país, devemos lembrar-nos da atual estrutura direcionada a partir de 2006, com a indicação das adequações curriculares e o fortalecimento da formação de professores via curso de Pedagogia, pois parece que não houve tempo suficiente para a produção de tal feito, como colocado.

As questões ligadas aos problemas de formação e colocadas em nosso país desde sempre são muito mais complexas e, infelizmente, ainda não foram sanadas. Mas, por outro lado, nos remetem a reflexões mais aprofundadas sobre o curso de Pedagogia em vigência.

\section{Um curso nem sempre valorizado}

Se analisarmos historicamente a atuação e a formação de professores em nosso país, e mais precisamente o curso de pedagogia, identificaremos grandes questões a serem repensadas.

As preocupações frente à formação de professores e ainda mais sobre a formação desses professores formadores foram negligenciadas por muito tempo e ainda distanciadas das questões relacionadas ao ensino superior.

Podemos dizer que, desde sempre a educação foi desprestigiada. O reconhecimento e prestígio de se cursar as universidades, via de regra não estavam relacionados à carreira do magistério.

Quando pensamos em um histórico sobre a formação de professores no Brasil, via o curso de Pedagogia, não podemos desconsiderar todo um percurso mais amplo existente da atuação dos professores em nosso país, praticamente desvinculado dos processos de formação e, ainda muito distante do curso de Pedagogia.

Em linhas gerais, ao considerarmos o percurso histórico do exercício da docência identificaremos uma estreita relação desta com a Igreja, uma vez que inicialmente cabia apenas aos religiosos a responsabilidade pela educação no Brasil, principalmente representado pelos jesuítas.

Podemos dizer que esses professoresreligiosos eram diretamente relacionados ao imaginário de bondade, virtuosidade e doação. Segundo Adorno (2000), essa adoração dispensada aos professores está presente em vários países e se fortalece em países em que o magistério é vinculado à religião. Como diz Adorno (2000), "O aspecto mágico da relação com os professores parece se fortalecer em todos os lugares onde o magistério é vinculado à autoridade religiosa [...]" (p.104).

Posteriormente, com a vinculação da educação ao Estado, o exercício da docência passa a ser representado pelos leigos e a ser atrelado às políticas de Estado que são construídas para o atendimento da população. Mas mesmo distanciando-se da vinculação religiosa, o trabalho dos professores ainda manteve-se ligado à identidade religiosa, como sacerdócio, dom para o exercício da docência. 
Durante grande período de nossa história, a existência de professores, sejam eles religiosos ou leigos, esteve desvinculada das questões de formação desses professores frente à atuação que tinham ou teriam. Desse modo,

o estabelecimento das escolas destinadas ao preparo específico dos professores para o exercício de suas funções está ligado à institucionalização da instrução pública no mundo moderno, ou seja, à implantação das idéias liberais de secularização e extensão do ensino primário a todas as camadas da população (TANURI, 2000, p.62).

A necessidade da formação de quadros frente à ampliação do oferecimento de educação à população e as medidas adotadas para se atender a essas necessidades, marcaram a indicação da carreira por processos acelerados, facilitados ou mesmo simplificados de formação, oferecidos em níveis anteriores ao ensino superior e/ou "remendados", fatos que marcam as concepções acerca da profissão até hoje.

Nesse histórico, a atual LDB (Lei 9394/96) foi promulgada após anos e anos de discussões, recebendo muitas críticas sobre o texto que finalmente foi votado e aprovado. A mesma trouxe em seu bojo desacertos quanto às intenções e espaços de formação que permanecem até hoje.

No texto da Lei 9394/96 há a indicação de que a formação para a atuação na educação básica ocorra em nível superior, com a delimitação de um prazo para que os sistemas de ensino de adéqüem, conhecido como a década da educação, prazo esse ampliado posteriormente pelo Plano Nacional de Educação. Porém, abriu uma distinção de espaço de formação: os Institutos de Superiores de Educação e a Universidade.

\section{Art. 62}

[...] a formação de docentes para atuar na educação básica far-se-á em nível superior, em curso de licenciatura, de graduação plena, em universidades e institutos superiores de educação. [...] (BRASIL, LDB, 1996).

Evidenciou-se uma sobreposição agora não mais da formação em níveis diferentes de ensino, como era até então, mas agora no mesmo nível, o superior, sobreposição esta entre o Curso de Pedagogia e o Curso Normal Superior.
Quanto à dicotomia e/ou sobreposição de formação, esta esteve presente na estrutura do curso desde seu início, pois possibilitava a formação de bacharéis e de licenciados, ou seja, dois tipos de diplomas. A licenciatura via "curso de didática", que assim era denominado, não era oferecida e destinada apenas aos bacharéis em pedagogia, mas a todos os interessados em complementar sua formação de bacharelado com uma licenciatura. E, ainda, os bacharéis em Pedagogia "[...] fariam apenas duas das seis disciplinas, pois as demais poderiam ser eliminadas por equivalência. Fica claro, portanto, que o 'curso de didática' era voltado para bacharéis de outras áreas que poderiam buscar a licenciatura" (ASSIS, 2007, p. 34).

Mais um episódio de desvalorização do professor é demarcado com a ideia de facilitação na formação, e até mesmo desqualificação da importância de sua formação, pois em apenas seis disciplinas era possível formar o professor - o licenciado - professor habilitado a exercer a docência. Vale destacar aqui que, apesar da indicação para a docência, esta ainda é ligada a atuação nos cursos normais.

Somente na década de 1960 encontraremos as primeiras discussões frente à incursão dos professores egressos do curso de Pedagogia na atuação do ensino de $1^{\circ}$ grau (ensino fundamental). Mas essa discussão não era exatamente frente às questões de melhoria da qualidade do ensino, era uma discussão frente a uma dada incoerência, assim entendida, de como quem poderia formar o professor que iria atuar no ensino primário, não poderia, ele mesmo, lá atuar.

Foram muitas idas e vindas durante esse histórico e nem a primeira LDB, Lei 4024/61, nem a lei da Reforma Universitária, Lei 5.540/58, indicaram de maneira assertiva que a formação ocorresse em nível superior.

Entre as reformas do regime militar, a reordenação do ensino superior, decorrente da Lei 5.540/68, teve como conseqüência a modificação do currículo do curso de Pedagogia, fracionando-o em habilitações técnicas, para formação de especialista, e orientando-os tendencialmente não apenas para a formação do professor do curso normal, mas também do professor primário em nível superior, mediante o estudo da Metodologia e Prática de Ensino de $1^{o}$ Grau (TANURI, 2000, p. 80). 
Como indicado nas palavras de Tanuri (2000), existia uma orientação de tendência para a formação também do ensino primário, com a inclusão de uma disciplina específica a esse fim, mas não efetivamente a indicação da formação em nível superior. E ainda, segundo Assis (2007), com o Parecer 252/69 do CFE essa indicação perde-se quase que totalmente:

É no parecer 252/69 do CFE que a Lei da reforma universitária se faz presente no curso de Pedagogia, não delimitando apenas a profissão e o tipo de profissional que se terá formado no curso, como também se baseando nas necessidades do presente momento para indicar quais habilitações deveriam ser apresentadas [...] como coloca anteriormente, a visão do pedagogo como um especialista/técnico em educação permanece $e$ dita o organização da formação, já que a nova proposta é a formulação de um curso com dois momentos distintos: um que apresente uma base comum de estudos, pois se considera o setor educacional como um todo; e um segundo momento que visa atender as habilitações específicas, oriundas de ramificações a partir da base comum citada; são elas: orientação escolar, administração escolar, supervisão escolar e inspetor escolar, considerando, ainda, que independentemente da habilitação escolhida existia a possibilidade $e \quad o$ consentimento de que esses profissionais também fossem professores dos cursos normais (ASSIS, 2007, p.54-55).

Completando esse pensamento, Silva (2004) indica que "essa formação do especialista, imposta ao curso e Pedagogia, conduziu fatalmente a uma visão desintegradora do trabalho pedagógico, provocando a fragmentação da formação do Pedagogo" (p. 23).

Notamos assim, que as preocupações do curso não estavam voltadas à qualidade de formação do professor para a atuação em sala de aula, as preocupações voltaram-se para a administração da escola, distanciando-se da docência,

Com a Lei 5.692/71, o ensino passa a ser estruturado em $1^{\circ}$ e $2^{\circ}$ graus, com a criação de Habilitações a serem cursadas em nível de $2^{\circ}$ grau, dentre elas a Habilitação específica para o Magistério, que de alguma forma herda o espaço de formação de professores para o ensino no $1^{\circ}$ grau, mas agora podemos dizer já sem todo o prestígio da Escola Normal. "Além disso, desaparecem os Institutos de Educação e a formação de especialistas e professores para o curso normal passou a ser feita exclusivamente nos cursos de Pedagogia". (TANURI, 2000, p.80).

Podemos dizer que após a publicação das Diretrizes Curriculares Nacionais para o Curso de Pedagogia (2006), o foco de formação e se assim pudermos dizer, características e marcas para sua identidade, estão voltadas prioritariamente para a docência - a formação do professor - ficando em segundo plano a formação para a atuação em funções administrativas. Além disso, se ampliou os objetivos impostos aos processos formativos, esperando a formação e o preparo dos alunos também como pesquisadores, não necessariamente o pesquisador acadêmico, mas um profissional que possa e saiba ler a realidade da escola buscando, a partir dessa leitura, possíveis soluções para os desafios impostos.

Segundo Gatti (2010),

Essa licenciatura passa a ter amplas atribuições, embora tenha como eixo a formação de docentes para os anos iniciais da escolarização. A complexidade curricular exigida para esse curso é grande, notando-se também, pelas orientações da Resolução citada, a dispersão disciplinas que se impõe em função do tempo de duração do curso e sua carga horária, [...] (p. 1358).

Em um primeiro momento, o Decreto 3.276/99 indica que a formação de professores passa ser incumbência exclusiva dos Institutos Superiores de Educação, nos cursos Normais Superiores, mudada, posteriormente, pelo Decreto 3.554/2000, que altera o termo exclusivamente para preferencialmente e habilitando assim, o curso de Pedagogia, novamente para essa formação.

Em 16 de maio de 2006, é publicada a Res. 1/2006, as Diretrizes Curriculares Nacionais para o Curso de Pedagogia, com base, principalmente, nas reivindicações da ANFOPE e indicando que

No atendimento da ANFOPE a base da formação do Pedagogo deve ser a docência e, portanto cabe ao curso de Pedagogia contemplar uma formação teórica $e$ interdisciplinar sobre o fenômeno 
educacional e seus fundamentos históricos, políticos e sociais, bem como os conteúdos das áreas de conhecimento, como matemática, ciências, história, geografia, português, etc. (SILVA, 2004, p. 27).

As críticas apontam uma indefinição da identidade do profissional que deve se formar.

Finalmente tenta-se empreender algo que muito se almejou, a formação de professores em nível superior e por definição da legislação atual, no Curso de Pedagogia, curso esse que apresenta como base a docência e a atuação do pedagogo em outras instâncias e instituições relacionadas ao ensino. Mas, a questão da identidade da formação não foi resolvida, visto que as discussões se a docência deveria mesmo ser a base de formação do pedagogo continuam e seus defensores ainda buscam se fortalecer.

Além disso, os problemas estruturais, identificados por estudiosos, dessa formação nos cursos que são oferecidos, indicam que o processo de formação acontece de modo fragmentado. Segundo Gatti (2010),

[...] o que se verifica é que a formação de professores para a educação básica é feita, em todos os tipos de licenciatura, de modo fragmentado entre as áreas disciplinares $e$ níveis de ensino, não contando o Brasil, nas instituições de ensino superior, com uma base comum formativa, como observado em outros países, onde há centros de formação de professores englobando todas as especialidades, com estudos, pesquisas e extensão relativos à atividade didática e às reflexões e teorias a ela associadas ( $p$. 135).

As colocações de Gatti, além de Nóvoa e outros autores, geram novas questões ainda a serem consideradas na formação inicial de nossos professores.

\section{Ampliando o olhar}

O que os pesquisadores da área dizem sobre essa questão? Dizem que a formação inicial de professores não é o foco principal dos estudos realizados em teses e dissertações, na área de educação de nosso país.

A análise realizada por André (1999), sobre a formação de professores no Brasil na década de 90 traz a indicação e reorganização dos temas principais, sendo que no caso das teses e dissertações, encontramos as expressões: Formação inicial; Formação continuada; Identidade e profissionalização docente.

O exame das dissertações e teses defendidas no período de 1990 a 1996 mostra que a produção discente quase dobrou nesse período, porém os trabalhos que abarcam a questão da formação de professores não acompanharam esse crescimento, mantendo-se em quantidades ainda pequenas frente ao total das produções.

Os resultados indicam que,

[...] dos 284 trabalhos sobre formação do professor, produzidos de 1990 a 1996, um total de 216 (76\%) tratam do tema da formação inicial, 42 (14,8\%) abordam o tema da formação continuada e 26 (9,2\%), focalizam o tema da identidade $e$ da profissionalização docente (ANDRÉ, 1999, p. 302).

Nos trabalhos pesquisados, no que tange especificamente ao curso de Pedagogia e a identidade docente, encontramos os seguintes dados dos trabalhos produzidos: $76 \%$ estão relacionados a formação inicial, mas se considerarmos apenas os trabalhos relacionados ao curso de pedagogia e a identidade estes indicam que $18,2 \%$ dos trabalhos, apenas, estiveram relacionados com esse tema.

O tema "Identidade e profissionalização docente" é pouco explorado no conjunto das pesquisas, configurando menos de $10 \%$ do total das 284 dissertações e teses defendidas, mas emerge com certa constância nos últimos anos. Os conteúdos que se destacam nesse grupo de estudos são a busca da identidade profissional $e$ as concepções do professor sobre a profissão. Aspectos relacionados às condições de trabalho do professor e aos movimentos de sindicalização e organização profissional aparecem só nos últimos anos, mas ainda de forma muito tímida (ANDRE, 1999, $p$. 302).

Ao indicar que o curso de Pedagogia é pouco investigado, e que ligado ao tema identidade muitos outros assuntos são correlacionados e foram agrupados a ele, entende-se que 
Identidade e profissionalização docente surgem como tema emergente nos últimos anos, e abre perspectivas para questões de grande interesse e atualidade, como a busca da identidade profissional do docente, a relação do professor com as práticas culturais, questões de carreira, organização profissional $e$ sindical $e$ questões de gênero. (ANDRE, 1999, p.303)

Já a análise dos periódicos publicados entre os anos de 90 a 97 mostrou uma inversão desses números, merecendo destaque na quantidade de artigos identificados que versam sobre as questões de identidade e profissionalização.

Os temas mais enfatizados nos períodos foram: identidade e profissionalização docente, com 33 artigos (28,7\%); formação continuada, com 30 (26\%); formação inicial, com 27 (23,5\%) e prática pedagógica, com 25 (22\%) (ANDRE, 1999, p. 304).

Além das questões de identidade, também a categoria formação inicial foi identificada e nesta, seis artigos versavam sobre o curso de pedagogia, totalizando assim, 39 dentre os textos relacionados a identidade e ao curso de Pedagogia. Os conteúdos incluídos no tema identidade e profissionalização docente são: condições de trabalho e remuneração/socialização. Entendemos, portanto, que no agrupamento indicado como identidade muitos outros temas ganham destaque dentro desse número de pesquisas.

Note-se que a distribuição dos artigos pelos quatro temas foi muito mais equilibrada do que nas pesquisas dos discentes, que evidenciou grande concentração na categoria formação inicial. Note-se ainda que o tema mais freqüente nos artigos é o que aparece em último lugar na produção dos discentes (ANDRE, 1999, p.304).

Já na análise dos trabalhos apresentados no GT da Anped, no período de 1992 a 1998, vimos que esses números se invertem novamente e a indicação relacionada às questões de identidade diminui novamente. Dos 70 trabalhos analisados apenas 12 textos (17\%) estão ligados à identidade e profissionalização docente. Das discussões sobre formação inicial há 29 trabalhos, destes somente 8 (28\%) estão vinculados ao curso de pedagogia.

Os trabalhos sobre o curso de Pedagogia focalizam os movimentos de reformulação do curso no país; revelam as deficiências desses cursos, seja pela distância entre a proposta curricular e suas práticas, seja pela falta de articulação entre os docentes formadores, seja pela separação entre discurso e prática. Buscam, ainda, mostrar $o$ peso das representações relacionado à experiência familiar na relação professoraluno (ANDRE, 1999, p. 308).

Assim, a necessidade da busca, leitura e apropriação das pesquisas realizadas na área, após a realização e publicação desse estado da Arte da Formação de Professores no Brasil, justifica-se, como uma possibilidade de termos mais dados. Fato que de certo modo confirmou o que foi indicado até o momento, pois poucos foram os trabalhos encontrados em bases de teses e dissertações que se dedicaram aos estudos sobre formação de professores.

No quadro a seguir, indicamos o número de trabalhos selecionados, além de artigos e documentos que tratam das temáticas que consideramos relacionadas ao nosso estudo.

\begin{tabular}{|c|c|c|c|c|c|}
\hline Temáticas & $\begin{array}{l}\text { Formação de } \\
\text { professores }\end{array}$ & $\begin{array}{l}\text { Curso de } \\
\text { pedagogia }\end{array}$ & $\begin{array}{l}\text { Formação do } \\
\text { pedagogo }\end{array}$ & $\begin{array}{l}\text { Identidade } \\
\text { docente }\end{array}$ & $\begin{array}{l}\text { Identidade do } \\
\text { pedagogo }\end{array}$ \\
\hline Tese & 01 & 02 & & & 02 \\
\hline Dissertação & 02 & 02 & 07 & 04 & 03 \\
\hline Artigos & 09 & 01 & & & \\
\hline Documentos & 04 & 02 & & & \\
\hline
\end{tabular}

No período entre 2006 e 2012 ( $1^{\circ}$ semestre) encontramos cinco teses, dezoito dissertações, dez artigos e seis documentos que versam sobre formação de professores no Brasil.

\section{Considerações Finais}

Nossas esperanças são apontadas a seguir por meio de postulados que acreditamos revelar 
uma posição política clara na luta pela melhoria da qualidade do curso de Pedagogia em nível superior.

1) As duras críticas direcionadas ao curso de Pedagogia não fazem deste um curso menor ou de menos valor.

2) $\mathrm{Se}$ o curso de Pedagogia é fragmentado, os demais cursos de graduação também o são, pois para se formar em três anos, por exemplo, e entrar em contato com os principais conteúdos do curso escolhido, não há como não ser.

3) A falta de articulação entre os docentes é resultado do contrato de trabalho dos decentes-horistas, e tal fato não acontece apenas em cursos de Pedagogia, mas principalmente nas instituições particulares que têm esse regime de trabalho.

4) A distância entre discurso e prática pode ser notada entre diferentes cursos no Ensino Superior e isto demonstra a dificuldade de colocar em prática teorias por vezes muito adequadas, mas que esbarram no sistema e na cultura escolar. O que não acontece apenas nos cursos de Pedagogia.

5) A contratação de docentes para o ensino superior que não possuem experiência profissional no campo da educação traduz uma realidade econômica-financeira presente em nosso país, na qual o profissional de qualquer área precisa optar entre um ou outro emprego por incompatibilidade de horários.

Isto posto, perguntamos ainda: a área de humanidades é tão respeitada quanto as das demais ciências? As demais licenciaturas são analisadas ou a "culpa" recai apenas sobre os cursos de Pedagogia? Quem tece críticas ao curso de Pedagogia é pedagogo?

A conscientização das fragilidades do curso de Pedagogia nos leva a pensar que talvez não tenhamos conquistado um elevado estágio de consciência política que nos faça analisar e criticar a educação em toda sua complexidade e contextualização.

Criticidade, curiosidade e criatividade integram a complexidade das relações que situam a conscientização no campo das possibilidades e não das certezas, desafiando a autoria do inédito-viável no trabalho de formação de educadores (STRECK, REDIN, ZITKOSKI, 2008).

Para enfrentar questões desafiadoras, como: qual o futuro que projetamos para o curso de Pedagogia se conhecemos a complexidade do presente com suas fragilidades? Que ações podemos empreender para evitar a acomodação ou a fuga? concluímos com o pensamento de Freire (2000) que nos inspira: "O futuro não nos faz. Nós é que nos refazemos na luta para fazê-lo" (p.27).

\section{Referências}

ADORNO, Theodor W. Educação e Emancipaçãa. $2^{a}$ edição. Tradução Wolfgang Leo Maar. Rio de Janeiro: Paz e Terra, 2000.

ANDRÉ, Marli. Estado da Arte da Formação de Professores no Brasil. Revista Educação e Sociedade, ano XX, nº 68, 1999.

FREIRE, Paulo. Pedagogia da esperança. Rio de Janeiro: Paz e Terra, 1992.

FREIRE, Paulo. Pedagogia da indignação. São Paulo: UNESP, 2000.

GATTI, Bernardete. A Formação de Professores no Brasil: Características e Problemas. Educ. e Sociedade, v.31, n 113. Campinas, 2010.

GONÇALVES, Luciana dos Santos. O curso de pedagogia e o processo de construção da identidade do pedagogo. Dissertação de mestrado. Campinas: PUC, 2010.

SILVA, Elizabeth Vieira Matheus. A formação do Pedagogo: um estudo exploratório de três cursos de Pedagogia à luz das diretrizes curriculares nacionais. Dissertação de mestrado. Florianópolis: UDESC, 2004.

STRECK, Danilo R., REDIN, Euclides \& ZITKOSKI, Jaime José. Dicionário Paulo Freire. Belo Horizonte: Autêntica, 2008.

TANURI, Leonor Maria. História da formação de professores. Revista Brasileira de Educação, $n^{\circ}$ 14. Universidade Estadual de São Paulo, 2000.

\section{Endereços Eletrônicos}

http://portal.mec.gov.br (acesso em 04 de julho de 2012).

http://veja.abril.com.br/261108/entreviste.shtml (acesso em 05 de julho de 2012). 
www.jornaldaciência.org.br (acesso em 06 de julho de 2012).

Sobre as autoras:

Margarete Bertolo Boccia: Doutoranda e Mestre em Educação. PPGE -UNINOVE - SP

Mônica de Ávila Todaro: Doutora em Educação - UNICAMP - SP. Docente da UNINOVE - SP

Recebido em: 10/2012

Aprovado em: 06/2013 